\title{
Relevant Problems of Personnel Training for The Real Sector of The Economy Based on The Competency-Based Approach in Education
}

\author{
N.A. Moiseenko ${ }^{*}$, V.M. Serov ${ }^{1}$, O.E. Astafieva ${ }^{1}, T . Y u$. Shemyakina ${ }^{1}$, and A.V. Kozlovsky ${ }^{1}$ \\ ${ }^{1}$ State University of Management, Department of Psychology, Economy and Management in \\ Building, Moscow, Russia
}

\begin{abstract}
Specialists' level of professional training gains special significance in modern economic conditions. This problem is also relevant to organizations of the real sector of the economy. The present article examines the problems of training personnel for various economy sectors related to the competency approach adopted in the education system. Increasing the level of training of managerial personnel while accounting for industry characteristics and their specialization profile is noted to be one of the priority directions of work. The study is based on Russian practice in developing the country's production potential and on the practice of scientific, technical, and economic development of foreign countries, particularly Japan, China, and others. The requirement of quantitative and qualitative staffing is an indispensable condition for the effective functioning and development of enterprises and organizations of all sectors and spheres of the national economy. In this regard, the goal of the present study is to identify, analyze, and summarize the positive and negative aspects of the competency approach to educational practice. Attainment of the set goal is based on the methodological approaches to the assessment of the existing educational system and the methods of comparative analysis of general economic consequences of such changes from the employer's perspective. The scientific result of the study is the ways of resolving the identified problems suggested by the authors from the point of both the employers and the directions of the professional activity of higher and secondary special educational institutions. In particular, it is suggested to create corporate training centers at large organizations, the ideology of which would be based on improving the professional level of employees in accordance with the established qualification requirements.
\end{abstract}

\section{Introduction}

The requirement of quantitative and qualitative staffing is an indispensable condition for the effective functioning and development of enterprises and organizations of all sectors and spheres of the national economy. This direction is taken by higher educational institutions development programs allowing to develop the knowledge and skills of their teaching staff

* Corresponding author: na moiseenko@guu.ru 
[1-3]. At the same time, these programs often remain ineffective due to its participants not making full use of what they learned in their professional practice [1]. It should be noted that in the period of economic reforms carried out in Russia, serious changes have occurred both in the staffing of enterprises and organizations and in the field of employee training.

The analysis of the practice of enterprises and organizations demonstrates a substantial decrease in staffing levels at all levels from managers and division specialists and technical and managerial services to regular workers. This phenomenon is characteristic of practically all industries, construction, transport, and housing and communal services. The average age of highly qualified personnel typically exceeds the critical line and is about 56-58 years old. A certain exception is presented by organizations in the field of communication and information services. The demand of enterprises and organizations for highly qualified engineering staff is not satisfied. At the same time, the labor market experiences an excess of personnel in economics and management who, in addition, demonstrate an insufficient level of knowledge and preparedness for practical work. As A. Leibovich notes, it can be concluded that a personnel crisis regarding the quality and structure of employees is present in Russia [4].

The reasons for the unfavorable situation in the area of staffing formed in many industries and sectors of the economy are not only the overall process of reformation of the economy, the change in its structure, and the processes of downfall and stagnation but also the specific destruction of the system of staff training previously existing in the country and the insufficient degree of its reformation not meeting the modern requirements. In this regard, we can present a statement about defining the requirements for staff training for the real economy sector in higher professional education as a hypothesis: an informed decision on who to train, what the requirements for training specialists should be, what should the content of training include and how and based on what methods should the training be organized. Therefore, the goal of the present study is to examine the positive and negative sides of the competency approach in education and evaluation of the quality of a resulting specialist from the point of university staff and potential employers.

\section{Methods}

The questions of who to train and what the requirements for trained specialists are, i.e. what the content of their training should be and how should the training be executed are central in training personnel for the real sector of the economy in the sphere of higher professional education. The programs of teacher training in higher education are aimed at the development of their knowledge and skills. The programs typically pursue the goal of developing approaches to education, education strategies, developing courses, educational programs, and practices of teacher assessment and identification [5-7]. At the same time, empirical results demonstrate only moderate improvement in the effectiveness of training of the participants of such programs and a lack of improvement in the results of students' learning. For example, Taylor and Znaida [8] identify various training development outcome templates which indicates the importance of a reliable network of teachers to learning improvement [9]. Convincing data is indicating that teacher training development programs are not always as effective as the context requires $[1,10,11]$ and the effect of teacher training development on the effectiveness of learning is not always studied systematically $[7,12]$.

The typically adopted indicators of competence of any employee, specialist, worker, middle and senior manager in the practice of labor management in the general system of industrial and economic management are knowledge and skills. Thus, the attestation of a worker aimed to identify their compliance with their specific professional qualification involves applying pre-formulated requirements regarding knowledge in the area of their professional duties and skills necessary for its execution. Overall, this is defined as 
qualification requirements. Compliance with current production standards while ensuring the required level of quality of work is an integral part of the qualification requirements for working professions. Similar qualification requirements for workers are presented in construction and all types of work in other sectors: industry, transport, agriculture, housing and communal services, etc. [13].

Qualification requirements also exist and are viewed as necessary for managers and specialists of the corresponding levels of technical management and organizational and economic management in all sectors of production, transport, and other areas of production, business, and economic and social activities. Heads of the management apparatus services have to possess knowledge and skills required to organize the work of specialists in the corresponding area of management entrusted to them and the specialists of the abovementioned services also have to have knowledge and skills allowing to execute the corresponding functions and perform specific work a part of which is standardized not so much in its content as it is in its form. A different part of work in an organization is not strictly individual in its form, especially the one related to planning, primary cost accounting, and analytical work related to finding internal reserves to increase production efficiency. A condition necessary for the successful work of specialists and their professional growth is the overall level of knowledge of their specialization. Comprehensive ability to execute the duties specified in job descriptions and requirements efficiently and on time is mastered to the extent and in accordance with the professional advancement of a specialist but to begin to master the work to be completed a worker needs special skills that specialists trained in higher educational institutions acquire in the process of completing practical assignments, course projects and works, undergoing practical training, and during the preparation of final qualifying works.

\section{Results}

In the process of examining the training of future personnel in the educational institutions of higher and secondary professional education, we have to note a drawback of modern bachelor training - a sharp decrease in the number of course projects and work in specialized disciplines, a limitation of possibilities for obtaining practical skills. Quite apparently, it is impossible to train managers in an instant even if students master all the suggested disciplines. Educational institutions train specialists in corresponding specialties and various levels of preparedness. Specialists then become managers in the process of professional activity along with the accumulation of experience and practice in the management of production, production and economic activity, and labor collectives. Training and professional development of managers are still in the field of postgraduate education [14]. The organization and functioning of a training center in Bremen (Germany) can serve as an example of training and advanced training of construction workers. At their own expense, twenty-nine largest construction companies organized and maintain a training center located in the city on a piece of land allocated by the municipality [15].

Concerning the requirements for the training of specialists with higher and secondary professional education of the first level, particularly the assessment of their preparedness for practical activity, the following conceptual conclusion can be drawn based on the provided example from the sphere of construction (which can also be true for other spheres of production and economic management): the main characteristics of preparedness of the alumni of higher and secondary professional educational institutions are knowledge and skills, more specifically - production skills. The competency approach in education involves the acquisition of knowledge and basic and specific skills. This approach always served as a base for training in the system of professional education in this exact interpretation. 


\section{Discussion}

The authors of the two-level system factually reduce the qualification assessment of alumni - future workers - to a single component of "qualification" that, judging by the interpretations of general cultural competencies, is understood as specific skills of executing work or special operations of different levels of complexity titled as ability [16]. Thus, the authors of this "new idea" consider an ability and the worker's skill in performing their professional activity to be the same. However, the concepts of "competency", "ability", and "skill" each represent a corresponding essense of mental, psycho-physiological, and physical condition of a working person. According to the established understanding, a competency is knowledge, awareness in a certain field. There is no need to substantiate the obvious fact that the execution of any type of work, completing an operation of labor requires specific knowledge of varying levels and volume. Therefore, being competency-oriented both in its essence and content, the existing approach in professional attestation of workers in assigning the appropriate categories to them sets the criterion of "must-know" as the main one. However, with specific exceptions, the knowledge alone is not enough for the execution of work and labor duties. Specific skills of varying degrees are also required. The development of initial skills is preceded by the acquisition of skills, and then the skills of workers develop from simple to complex and expand along the process of work. Here, the abilities of a person serve as a condition for their acquisition of knowledge and skills.

Abilities are not reduced to the knowledge and skills possessed by an individual. They are rather found in the speed, depth, and stability of mastery of the ways and techniques of a certain activity and present inner mental regulators determining the ability to master these techniques. Thus, a person's abilities are not something given to them by nature. In this regard, we agree with $\mathrm{V}$. Serov who considers the abilities of every person to be naturally different in the areas of activity and in the degree of acquisition of knowledge and skills. Abilities can and should be developed. The realization and development of abilities help a person acquire the corresponding level of knowledge and skills in a certain area of labor activity [17]. The study and knowledge of people's abilities are highly important in a practical sense for vocational guidance, professional selection, and in the process of training in corresponding professions. The analysis and assessment of abilities involve various methods, including testing. As we can see, in the construction of the competency approach, its authors allowed what is called "the mixing of concepts" in science and the practice of logic. What takes place here is a replacement, substitution, and confusion of established encyclopedic concepts and provisions of psychology as the science of person and the science of labor as an expedient human activity. Moreover, this confusion is not strictly theoretical but occurs in the sphere of specific characteristics of a working person.

\section{Conclusion}

Therefore, the "reinvention" of the competency approach in education practically presents its impoverishment and is harmful for professional education. Modern specialists and managers at all levels of production management have to possess knowledge both in the field of production engineering and technology and in economics and production organization and management. The realization of the Bologna Agreement on higher education and the executed transition to two-level education of employees with higher professional education organized in accordance with the "bachelor" - "master" scheme involves the acquisition of general management knowledge in the spheres of engineering and technology or management by alumni at the bachelor level in four years and the subsequent progression to the magister level in two years. However, the indicated six years of study and training for the magister's degree do not provide students with the required knowledge and skills both in 
technology and in economics and production management. The knowledge is deepened only in one of the directions. Therefore, most enterprises and organizations in almost all of the areas of the real sector of the economy experience a shortage of trained and qualified workers and managers.

Therefore, the creation of functional training centers in large industry companies with the goal of improving the skills of managers, mid-level professionals, and workers will ensure the professional growth of workers taking into account the industry characteristics.

Moreover, it is necessary to restore the specialist degree in the sphere of engineering and pedagogical education. This was noted at the Penza Pedagogical Forum (October 2019) where the need for the realization of suggestions on training specialists with an "engineermanager" qualification (by the branches of material production - industry, construction, transport, housing and communal services, etc.) with a five-year-long period of training was discussed. The practice of training and activity of said specialists have proven itself positively. The indicated specialists were taught in 70 universities and faculties and they were highly demanded by employers. Deriving from the positive practice in the past, it appears to be expedient to return to graduation of specialists with the specified content of training. Moreover, in this case, the time and expenses of training the specialists that would suffice the needs of the production will decrease in a part of the real sector of the economy.

In conclusion, we have to note that the hypothesis proposed by the authors of the present article and the set goal of the study were disclosed and justified, although enough questions remain in need of examination and further resolution.

\section{References}

1. K. Leslie, L. Baker, E. Egan-Lee, M. Esdaile, S. Reeves, Acad. Med. 88, 1038-1045 (2013)

2. L. Postareff, S. Lindblom-Ylänne, A. Nevgi, Teach. Teach. Educ. 23, 557-571 (2007)

3. A. Stes, L. Coertjens, P. Van Petegem, High. Educ. 60, 187-204 (2010)

4. A.N. Leibovich, Training system: growth points. Collection of methodological and informational materials (ANO "National Agency for the Development of Qualifications", Moscow, 2017)

5. E. Abu-Rish Blakeney, A. Pfeifle, M. Jones, L.W. Hall, B.K. Zierler, J. Interprofessional Care 30, 83-89 (2016)

6. A. Cheng, V. Grant, P. Dieckmann, S. Arora, T. Robinson, W. Eppich, Simul. Healthc. 10, 217-222 (2015)

7. T.T. Phuong, S.C. Cole, J. Zaretsky, High. Educ. Res. Dev., 37, 373-389 (2018)

8. K.L. Taylor, S.K. Znajda, Stud. Educ. Eval., 46, 39-46 (2015)

9. D.E. Froehlich, A. Gegenfurtner, Social support in transitioning from training to the workplace: a social network perspective, In book: Beziehungen in pädagogischen Arbeitsfeldern und ihren Transitionen über die Lebensalter, (Klinkhardt, Bad Heilbrunn, 2019)

10. K.E. Brinkley-Etzkorn, Internet High Educ. 38, 28-35 (2018)

11. A. Saroyan, K. Trigwell, Stud. Educ. Eval. 46, 92-101 (2015)

12. D. Chalmers, D. Gardiner, Stud. Educ. Eval. 46, 81-91 (2015)

13. V.A. Gusev, O.Yu. Nisman, Samara Scientific Bulletin 6(4(21)), 214-218 (2017)

14. D.O. Mongush, G.V. Panasenko, Alley of Science 3(10), 317-322 (2017) 
15. S.V. Normazinin, A brief collection of best practices for training personnel in the BRICS countries, Autonomous non-profit organization Agency for Strategic Initiatives to Promote New Projects Available at: http://asi.ru/upload/0b6/BRICS_ru_int.pdf

16. N.A. Semochkina, Bulletin of the Volgograd State Technical University 7(202), 39-43 (2017)

17. V.M. Serov, Theoretical and Scientific-Methodical Journal "University Herald" 10, 4247 (2019) 